\title{
A través del espejo: doble y alteridad en Borges
}

\author{
María del Carmen Rodríguez Martín
}

Facultad de Filosofía y Letras.

Universidad de Buenos Aires

El objetivo del artículo se centrará en abordar el concepto de identidad a través de las variaciones de la temática del doble en la obra borgesiana vinculadas propiamente con el doppelgänger - como caso particular de los cuentos en los que se encuentra consigo mismo - con los gemelos - como símbolo de lo dual en lo idéntico-y con la temática de los espejos - metáforas de la continua y utópica búsqueda de la identidad que existe únicamente como ausencia-. Por último, nos detendremos en el concepto de alteridad y su relación con el doble en cuanto encuentro del yo en el tú. En este sentido, el doble se nos muestra como posible vía de comunicación con el Otro en la medida en que éste se convierte en "otro yo" que comparte y otorga sentido a nuestra existencia.

PALABRAs Clave: Jorge Luis Borges, identidad, doble, alteridad.

This paper aims to show how in the work of Jorge Luis Borges the issue of the double is connected to the theme of the doppelgänger - the duplication is thematized in the stories in which Borges meets himself - to the twins — which symbolize the duality of the identical-and to theme of mirrors - which represent the continuous and utopic search of identity existent solely as an absence- L Lastly, this study examines the presence of the alterity which is conceptualized as an encounter of the "I" in the "you". In this sense, the double seems to communicate with the Other insofar as it becomes the Other of the "I", which shares and gives meaning to our existence.

KEYwORDS: Jorge Luis Borges, identity, double, alterity.

La ficcionalización del doble proporciona la posibilidad de extensión y conocimiento del propio yo y, simultáneamente, explicita la inherente inaccesibilidad a nosotros mismos. Por tanto, plantea el problema de la identidad en plenitud así como la necesidad de la alteridad como vía de completud y autognosis. En este sentido, el término doppelgänger, acuñado por Jean Paul Richter en 1796, pretendía concentrar estas ideas vinculándolas con las propuestas de la filosofía fichteana por las que el yo debía convertirse en un tú, tal y como explicitaría más tarde Martin Buber: "Cuando se dice Tú, se 
dice al mismo tiempo el Yo del par verbal Yo-Tú. (...) No hay Yo en sí, sino solamente el Yo de la palabra primordial Yo-Tú". ${ }^{1}$

Partiendo de "Borges y yo", donde asistimos a una división de la identidad como dos partes autónomas que dialogan y lo confrontan consigo mismo, nos detendremos en la figura del espejo como nuevo estanque donde contemplar y encontrarnos tanto con nosotros mismos como "otro" —identidad— como con "el otro" —alteridad—.

\section{"Borges y yo": La práctica del espejeo}

La tríada formada por los relatos en los que Borges se encuentra consigo mismo, "Borges y yo", "El otro" y "Veinticinco de agosto, 1983", constituyen un gran bloque temático en los que el autor argentino aborda el problema del doble. Los dos últimos poseen estructuras complementarias y ambos juegan con la idea de la permanencia de la identidad a través del tiempo. El encuentro y el reconocimiento en la diferencia introducen y sostienen la tesis de la movilidad del yo que es uno mismo - idem- y es otro -ipse-. Por este motivo, el "yo-otro", lo duplicado, se convierte en un referente extraño, diferente, circunstancia que desemboca en un enfrentamiento entre las dos caras de la identidad que reclaman su propio estatus ontológico. Por su parte, "Borges y yo" socava las bases de la identidad al confrontar el narrador, correlato del Borges empírico, con el Borges simbólico-autor, presentándonos una doble versión de sí mismo en donde se conjugan lo universal y lo particular, lo interior y lo exterior del aparecer fenoménico. De esta manera, se produce un repliegue del autor sobre sí que invoca la presencia del otro y el Borges narrado sustituye al Borges narrador acaeciéndose la emancipación de la imagen/objeto. Desde esta perspectiva, Borges contrapondría:

La búsqueda cartesiana de la sabiduría de lo cierto y lo seguro, de la verdad absoluta, en y por el yo pensante, [por] la búsqueda de la sabiduría de lo ambiguo y lo incierto, de las verdades relativas en el yo imaginario disuelto en sus máscaras y sus personajes. La búsqueda de la experiencia del yo conduce así a un 'yo experimental', no concluso e inesencial, que explora las posibilidades varias de la existencia en la pluralidad de sus personajes. $^{2}$

1 Buber, Martín: Yo y tú, Nueva visión, Buenos Aires, 1969, págs. 9-10.

2 Molinuevo, José Luis: La experiencia estética moderna, Síntesis, Madrid, 1998, pág. 198. 
En este sentido, resulta interesante interpretar este texto a la luz del análisis que realiza Pozuelo Yvancos acerca de la alteridad, el perspectivismo y el personaje en las propuestas de Bajtín y Ortega y Gasset en relación a la teoría de la novela. El relato de Borges se adecuaría a la ruptura que introduce el personaje en el orden mimético y representativo en la medida en que su discurso implica, simultáneamente, la actividad de decir y lo dicho. El personaje, que adquiere igual rango de realidad que el narrador, ya no es una cosa para un signo, sino que él mismo - Borges - se transforma en signo, en palabra. ${ }^{3}$ Asimismo, la conjura de la identidad/alteridad en el ser ficticio conlleva un desdoblamiento que posee cierta relación con la experiencia narcisista que Lacan denomina "estadio o fase del espejo". La autogeneración a través de la escritura comporta una caída en lo imaginario por la corrupción de lo simbólico y el lenguaje se constituye como la única manifestación que engloba lo individual y lo colectivo, lo objetivo y lo subjetivo. Desde este punto de vista, el ordenamiento, la sistematización y reconstrucción del yo sería uno de los caminos posibles para encontrar la unidad perdida y forjar la identidad. ${ }^{5}$ Sin embargo, la escritura posee una naturaleza dual en la medida en que es al mismo tiempo instrumento de salvación y perdición puesto que la narración nos muestra y nos diluye en las múltiples expresiones de nuestro yo.

Un ejemplo lo hallamos en el "Poema del cuarto elemento" en donde, por un lado, asistimos a la edificación del "yo Borges" a través de la palabra poética que lucha por capturar la fugitiva identidad reflejada en el agua. Sin embargo, la apariencia del otro, como imagen, como palabra, manifiesta la continua presencia de una ausencia, la huida constante de la identidad que se nos muestra como un laberinto de espejos múltiples metáforas de la inexistencia de una esencia a la que debemos fidelidad.

3 Pozuelo Yvancos, Jose María: Ventanas de la ficción. Narrativa hispánica, siglos XX y XXI, Península, Barcelona, 2004, pág. 24.

4 Recordamos brevemente las fases del la teoría lacaniana: en primer lugar, ante la percepción del reflejo el niño capta un ser real, su imagen es concebida como la imagen de otro, y reacciona ante ella con regocijo. En una segunda etapa, comprenderá que "el otro" del espejo es una imagen y no un ser real. En el último período, reconocerá al otro no sólo como imagen si no como "su imagen". La dialéctica del ser y del aparecer son el desencadenante necesario para conquistar la identidad del sujeto y su unidad corporal. Para Lacan, la existencia del hombre se caracteriza por la búsqueda constante de su identidad para lograr así encontrarse consigo mismo. Sin embargo, la conquista de la unidad perdida es imposible, motivo por el cual la convivencia en el plano de lo simbólico (el lenguaje) y el contacto con los otros son elementos necesarios para sentir reconocimiento y hálitos de completud. Palmier, Jean-Michel: Jaques Lacan. Lo simbólico y lo imaginario, Proteo, Buenos Aires, 1971, págs. 20-23.

5 Goloboff, Gerardo Mario: Leer a Borges, Yuca, Buenos Aires, 1978, págs. 164-165. 
La búsqueda de la propia imagen supone una indagación en la identidad personal y el estanque narcisista, el espejo y la escritura pierden su materialidad para constituirse en el espacio donde se reflejan los objetos y los sujetos comienzan a constituirse. ${ }^{6}$ Desde una perspectiva general, en la obra de Borges, el motivo del espejo alude al tema del doble y se relaciona directamente con los arquetipos platónicos, con la idea gnóstica que sostiene que el universo es una copia invertida del orden celestial y con la sensación de irrealidad que produce el reflejo y la multiplicación infinita de dos superficies especulares enfrentadas. ${ }^{7}$

Desde el punto de vista platónico, el verdadero sentido de este mundo se busca en lo Otro, en lo que está fuera del espacio sensible. Esta circunstancia nos conduce a la necesidad de una duplicación del modelo para dotar al mundo - la copia - de sentido. Sin embargo, la máxima socrática del conocerse a sí mismo es insuficiente en tanto que estamos incapacitados tanto para saber quién y qué somos así como para domeñar el entramado contextual en el que estamos inmersos:

La sentencia de san Pablo: Videmus per speculum in aenigmate sería una claraboya para sumergirse en el Abismo verdadero, que es el alma del hombre. La aterradora inmensidad de los abismos del firmamento es una ilusión, un reflejo exterior de nuestros abismos, percibidos 'en un espejo'. (...)

No hay en la tierra un ser humano capaz de declarar quién es, con certidumbre. Nadie sabe qué ha venido a hacer a este mundo, a qué corresponden sus actos, sus sentimientos, sus ideas, ni cuál es su nombre verdadero. ${ }^{8}$

El espejo pone de manifiesto el triunfo del simulacro, de la copia, advierte del fracaso de los nombres, de la transcripción del mundo en palabras y, desde un determinado punto de vista, convierte lo accidental en necesario, absolutiza lo fragmentario, dota de carácter eterno a lo contingente y manifiesta la catástrofe del pensamiento basado en categorías que no dejan de ser circunstanciales y subjetivas. ${ }^{9}$

Borges, habitante de la caverna, a través de la condición especular de sus relatos propone el concepto de frontera móvil como epistemología alter-

6 González Requena, Jesús: La metáfora del espejo, Hiperión, Valencia, 1986, pág. 15.

7 Barrenechea, Ana María: La expresión de la irrealidad en la obra de Borges, Biblioteca Universitaria, Buenos Aires, 1984, pág. 98.

8 Borges, Jorge Luis: Obras Completas, vol. II, Emecé, Barcelona, 1999, págs. 99-100.

9 Bulacio, Cristina y Grima, Donato: Dos miradas sobre Borges, Universidad Nacional de Tucumán, Buenos Aires, 1998, págs. 154-155. 
nativa. Recorriendo laberintos y espejos, como Velázquez en Las Meninas, "en su continua búsqueda de identidad, persigue utópicamente un centro que sólo existe como ausencia porque será siempre reflejo especular de algún otro centro invisible". ${ }^{10}$ Su obra nos conduce a una mise en abîme que explicita conceptualmente los reflejos infinitos, la ficción dentro de la ficción, hecho que afecta a nuestra creencia en la verdad de la percepción, ejerce una tensión entre lo que puede ser lógicamente aceptado y sensorialmente percibido y desestabiliza el principio de "identidad sustancial"."

Entre los textos en los que Borges explora y cultiva esta estructura, destacamos "Cuando la ficción vive en la ficción" y "Magias parciales del Quijote" donde realiza un recorrido por obras paradigmáticas que utilizan la estructura en abismo. Tal y como el escritor argentino expone, este "juego de (...) extrañas ambigüedades" aparece en la segunda parte del Quijote, donde los protagonistas son lectores de la misma obra a la que pertenecen, en Hamlet como representación de una tragedia dentro de otra y en la noche DCII de Las mil y una noches, en la que el rey escucha por boca de Sherezade su propia historia. De igual modo, señala el proyecto de Josiah Royce que podemos poner en conexión con la obra de Magritte "La traición de las imágenes (Esto no es una pipa)": ${ }^{12}$

Imaginemos que una porción de suelo de Inglaterra ha sido nivelada perfectamente y que en ella traza un cartógrafo un mapa de Inglaterra. La obra es perfecta; no hay detalle del suelo de Inglaterra, por diminuto que sea, que no esté registrado en el mapa; todo tiene ahí su correspondencia. Ese mapa, en tal caso, debe contener un mapa del mapa, que debe contener un mapa del mapa, y así hasta lo infinito. ${ }^{13}$

El regreso al infinito que sugiere la mise en abîme en Borges es conceptualizado por Jacques Derrida como "espejismo infinito" en cuanto nos es posible efectuar la lectura de un libro dentro de un libro, un origen dentro del origen, un centro dentro del centro como manifestaciones de una duplicación insondable e infinita. Así, insistimos, la ficción explora sus

10 Ricci, Gabriela: Las redes invisibles del lenguaje. La lengua en y a través de Borges, Alfar, Sevilla, 2002, pág.35.

11 Sarlo, Beatriz: Borges, un escritor en las orillas, Ariel, Buenos Aires, 1998, pág. 137.

12 Desde la perspectiva de la representación, Magritte pinta una pipa, únicamente la representación de la pipa. La obra de Magritte adaptaría los presupuestos esbozados por Foucault en "El lenguaje al infinito", donde defiende que: "[El lenguaje] impugna el lenguaje para reproducirlo en el espacio virtual (...) del espejo, y para abrir en éste un nuevo espejo, y otro más, y así hasta el infinito". Dallenbach, Lucien: El relato especular, Visor, Madrid, 1991, pág. 34.

13 Borges, Jorge Luis: Obras Completas, vol. II, Emecé, Barcelona, 1999, pág. 47. 
propias posibilidades, reta a las tradiciones, renueva la fe en la imaginación $\mathrm{y}$ descubre la ficcionalidad de la realidad y de la identidad. ${ }^{14}$

Por otro lado, la acción degradante que produce el reflejo con respecto al arquetipo así como el terror a la multiplicación infinita que aparece en textos como "Tlön, Uqbar, Orbis Tertius" o "El tintorero enmascarado...", es reiterada en poemas como "Al espejo": ${ }^{15}$ ¿Por qué persistes, incesante espejo?/¿Por qué duplicas, misterioso hermano,/el menor movimiento de mi mano?/¿Por qué en la sombra el súbito reflejo?/Eres el otro yo de que habla el griego/y acechas desde siempre. (...)/Cuando esté muerto, copiarás a otro/ y luego a otro, a otro, a otro, a otro....". ${ }^{16}$

El espejo en su continuo reflejo desperdiga la identidad. Los reflejos amenazan la existencia en cuanto nos transforman en apariciones fantasmales, en ídolos carentes de realidad:17 "Ya no estoy solo. Hay otro. Hay el reflejo". ${ }^{18} \mathrm{El}$ doble como imagen en el espejo asedia al sujeto "con una muerte sutil y siempre conjurada" y le recuerda su contingencia. ${ }^{19}$ El yo asume que es otro y siente la débil alteridad del sí que se busca en la quebrada identidad de la imagen. A su vez, el encuentro con el reflejo produce un enfrentamiento involuntario del yo consigo mismo que se percibe como objeto inasible al permanecer dentro de su mismidad percibiéndose únicamente como una sombra incapaz de capturar objetiva y totalmente nuestra visión y vivencia del mundo. En este sentido, matizará Bajtín: "vemos un reflejo de nuestra apariencia, pero no a nosotros mismos en medio de esta apariencia, (...) yo estoy frente a espejo pero no dentro de él; el espejo sólo puede ofrecer un material para la objetivación propia, y ni siquiera en su forma pura". ${ }^{20}$ Por este motivo, la postura ante el espejo tenderá a falsearnos al percibirnos como otro, posible e indefinido, con el que intentamos elaborar y vivificar nuestra identidad. ${ }^{21}$

14 Del Río, Carmen: JLB y la ficción: el conocimiento como invención, Universal, Miami, 1983, pág. 37.

15 Borges rememora el horror que le producía en su infancia la acción multiplicadora de los espejos: "Un temor que yo tenía cuando era chico, (...) era el gran ropero hamburgués de tres cuerpos con espejos. Estaba en mi dormitorio. Yo me veía reflejado tres veces. (...) De tanto en tanto abría los ojos para ver si uno de mis dobles o mis triples se había movido. ¿Y si lo hace, pensaba yo, voy a morirme de espanto?". Montecchia, M. P.: Reportaje a Borges, Crisol, Buenos Aires, 1977, pág. 96.

16 Borges, Jorge Luis: Obras Completas, vol. II, Emecé, Barcelona, 1999, pág. 510.

17 "Ídolos", en griego, significa "espectros, apariciones" o "imágenes" derivándose del verbo "ver", idon.

18 Borges, Jorge Luis: Obras Completas, vol. II, Emecé, Barcelona, 1999, pág. 193.

19 Baudrillard, Jean: De la seducción, Cátedra, Madrid, 1989, pág. 19.

20 Bajtín, Mijaíl: Estética de la creación verbal, Siglo XXI, México, 1990, págs. 36-37.

21 Ibídem, pág. 37. 
Sin embargo en ocasiones, como en "El tintorero enmascarado Hákim de Merv", los espejos abominan porque constatan precisamente este encuentro: la realidad de la cara carcomida por la lepra del apóstol de faz resplandeciente. Ante la incapacidad para aceptarse, el yo se disfraza, se enmascara para evitar verse y ser visto. La máscara engloba el deseo humano de expresión y ocultación en cuanto que manifiesta la voluntad de un aparecer de aquello que representa y un ocultar lo que se es. Su utilización supone la aspiración del hombre a ser lo que su limitación le impide y, en este sentido, la caída del velo, la eliminación de la máscara o el enfrentamiento con la imagen, suponen la exteriorización y la aceptación de nuestra radical indigencia. La máscara rompe con el sentido único de la existencia desgarrando los fundamentos de la identidad. Su utilización explicita el problema de la relación entre ser y apariencia - Vattimo dixit - y al engañar al espejo al ocultar el rostro provoca turbación e inquietud..$^{22}$ En general, los personajes que pueblan Historia universal de la infamia - a la que pertenece este relato- son y no son simultáneamente sus propias máscaras. Descritos por detalles accidentales y circunstanciales encuentran coherencia precisamente en el enmascaramiento. ${ }^{23}$ Según señala Bataille, el uso de la máscara revela la naturaleza enmascarada de un sujeto desgarrado, fraccionado y diluido. Esta circunstancia, manifestaría la ficcionalidad de la estabilidad del rostro, de la identidad y del cuerpo del hombre. ${ }^{24}$

Así, los personajes en los que Borges se desdobla son representaciones que dotan de vida a un disfraz vacío. Los textos únicamente representan el reflejo de un yo que es otro no conocido y que aspira a desentrañarse a través de la escritura/espejo.

\section{Variaciones sobre la alteridad}

Una de las variables del tema del doble que ocupa un lugar privilegiado en la cultura occidental como símbolo de lo dual en lo idéntico es la de los gemelos. En esta variación se encuentra implícita la vertiente narcisista por la que cada elemento tiende a convertirse en el espejo del otro y, a la vez, nos propicia una vía de análisis del concepto de alteridad.

22 Barnatán, Marcos Ricardo: Jorge Luis Borges, Júcar, Madrid, 1972, pág. 19.

23 Molloy, Silvia: Las letras de Borges, Beatriz Viterbo, Rosario, 2000, pág. 45.

24 Navarro, Ginés: El cuerpo y la mirada. Desvelando a Bataille, Anthropos, Barcelona, 2002, págs. 148-150. 
Sin duda, la pareja de hermanos por antonomasia es la de Caín y Abel. Borges reescribe su historia en varias ocasiones. Por ejemplo, en "La intrusa" encontramos la presencia de un Caín que amenaza la armonía de la relación entre los hermanos Nilsen quienes deciden asesinar a la Juliana para eliminar de raíz la semilla de la discordia que su presencia había sembrado entre ambos. Otra variación la hallamos en "Milonga de dos hermanos" donde la tensión dramática y existencial de la narración bíblica se concentra en Caín abrumado por la envidia y el odio que brotan de su posición desfavorable con respecto a su hermano: "Cuando Juan Iberra vio/que el menor lo aventajaba,/la paciencia se le acaba/y la armó no sé qué lazo/le dio muerte de un balazo,/(...) ...es la historia de Caín/ que sigue matando a Abel". ${ }^{25}$ De estos versos se desprende cierta visión cíclica de la historia que rememora y repite los acontecimientos como particularizaciones de un universal. Así, cada muerte reactualiza el primer homicidio tal y como recuerda Borges en "Nueva refutación del tiempo": “...para la justicia de Dios, el que mata a un solo hombre, destruye el mundo; si no hay pluralidad, el que aniquilara a todos los hombres no sería más culpable que el primitivo y solitario Caín". ${ }^{26}$ Siguiendo esta misma línea, en "Inmemoria J.F.K.", realiza una genealogía de la bala que mató al presidente estadounidense hasta llegar a la piedra que mató a Abel: "Antes, la bala fue otras cosas, porque la trasmigración pitagórica no sólo es propia de los hombres. (...) En el alba del tiempo fue la piedra que Caín lanzó contra Abel" ${ }^{27} \mathrm{La}$ misma idea está presente en "Génesis IV, 8": "Fue en el primer desierto./Dos brazos arrojaron una gran piedra./No hubo un grito. Hubo sangre./Hubo por vez primera la muerte./Ya no recuerdo si fui Abel o Caín". ${ }^{28}$

Por tanto, los hermanos bíblicos representan el antagonismo de lo íntimamente ligado y son símbolo de la primera piedra homicida como acontecimiento originario del enfrentamiento entre los hombres y del hombre consigo mismo.

Sin mantener la relación filial que une a los protagonistas de las obras anteriores, el tema cainítico está presente también en "Los teólogos" donde la problemática del doble aparece ligada a la especularidad a partir de las ideas gnósticas. Por otro lado, Borges plantea que este cuento es "un

25 Borges, Jorge Luis: Obras Completas, vol. II, Emecé, Barcelona, 1999, págs. 333-334.

26 Ibídem, pág. 141.

27 Ibídem, pág. 231.

28 Borges, Jorge Luis: Obras Completas, vol. III, Emecé, Barcelona, 1999, pág. 91. 
sueño melancólico sobre la identidad personal", circunstancia que nos induce a pensar que aunque el título sea plural, el protagonista es único: Aureliano. Juan, el otro, aparece en relación con él, como su reflejo. El odio sustenta la tensión y la relación entre ambos: Aureliano detesta a Juan, pero no logra vivir alejado de su presencia, lo rechaza para huir de su verdadera necesidad. Odiar a Juan implica odiarse a sí mismo, matarlo implica su propio suicidio y tras cumplir su tarea de justiciero asume la pérdida de su identidad, del sentido de su destino sobre la tierra en la medida en que se produce la falta de referente contra/con el cual definirse. Un tratamiento semejante al borgesiano lo encontramos en dos obras de Miguel de Unamuno: Abel Sánchez y El otro. Los (prot)agonistas unamunianos, caracterizados por un marcado rasgo existencialista, sufren el amor y el odio - de nuevo, la dualidad - como experiencias ontológicas fundamentales de su trazado vital considerado paradigmáticamente como la concreción individual del arquetipo "hombre" enfrentado a una realidad circundante en la que no encuentra la posibilidad de realizarse auténticamente.

En Abel Sánchez, Unamuno, como Borges, reelabora el mito bíblico de los hermanos primeros y convierte a Joaquín Monegro en el correlato de Caín. Esta identificación le permite reflexionar sobre cuestiones fundamentales como el destino trágico, la soledad, la envidia y la necesidad de comunicación. Lo novedoso del planteamiento unamuniano respecto a la versión del Génesis es la enunciación de la tesis de la predestinación de Caín y su carencia de libertad al cometer el acto homicida. ${ }^{29}$ La lucha de Caín, como la de Joaquín, es contra su destino. ${ }^{30} \mathrm{La}$ virulencia de su odio es tal que necesita que Abel siga existiendo para dar sentido a su existencia, al igual que Aureliano precisaba de Juan. La consecuencia inmediata de este sentimiento es la falta de capacidad para amar y comprender que puede ser amado, es decir, la imposibilidad de salir de la esfera del yo —egoísmo- al encuentro con el otro: "Yo no amo al prójimo, no puedo amarle, porque no me amo, no sé amarme, no puedo amarme a mí mismo". ${ }^{31}$ Sin embargo, esta deficiencia lleva aneja la paradójica necesidad de los otros para definirse, la necesidad del otro como "no-yo" para la constitución de la propia individualidad. Desde este punto de vista, la relación entre Caín/Abel y

29 “Odio? Aún no quería darle su nombre, ni quería reconocer que naci[ó], predestinado, con su masa y con su semilla. Aquella noche nacía al infierno de [su] vida". Unamuno, Miguel de: Abel Sánchez, Cátedra, Madrid, 1998, pág. 97.

30 Ibídem, pág. 34.

31 Ibídem, pág. 152. 
Abel/Joaquín, Aureliano/Juan puede entenderse como el anverso y el reverso de una misma moneda. ${ }^{32}$

En la pieza teatral El otro, el asesinato de uno de los miembros de la pareja de hermanos Cosme y Damián por parte de "El Otro" — uno de ellos - se constituye en el desencadenante de la crisis de identidad que previamente la duplicidad había cultivado. El gemelo/reflejo impide la realización del individuo al vetarle el acceso al alcanzar autenticidad/unicidad:

Desde pequeñito sufrí al verme fuera de mí mismo..., no podía soportar aquel espejo..., no podía verme fuera de mí... El camino para odiarse es verse fuera de sí, verse otro. (...) Nos hicimos malos los dos...Cuando uno no es siempre uno se hace malo...Para volverse malo no hay como tener de continuo un espejo delante, y más un espejo vivo, que respira... ${ }^{33}$

Esta aspiración de unidad, que exige la escisión y liberación del doble-gemelo, se encuentra estrechamente unida a la pulsión contraria, que produce la confusión y pérdida de identidad ante la identificación completa que desemboca en indistinción:

¿Yo? ¿Asesino yo? Pero ¿quién soy yo? ¿Quién es el asesino? ¿Quién el asesinado? ¿Quién el verdugo? ¿Quién la víctima? ¿Quién Caín? ¿Quién Abel? ¿Quién soy yo, Cosme o Damián? (...) Los dos mellizos, los que como Esaú y Jacob se peleaban ya desde el vientre de su madre, con odio fraternal, con odio que era amor demoníaco, los dos hermanos se encontraron...Era al caer de la tarde. (...) ¡Odia a tu hermano como te odias a ti mismo! Y llenos de odio a sí mismos, dispuestos a suicidarse mutuamente, por una mujer..., por otra mujer..., pelearon...Y el uno sintió que en sus manos, heladas por el terror, se le helaba el cuello del otro. ${ }^{34}$

¿Yo? Uno y otro, Caín y Abel, ¡verdugo y víctima! ${ }^{35}$

Paralelamente, en "Los teólogos" la identificación y la unión de/en la dualidad — alteridad - acontecen cuando Aureliano descubre que él y Juan de Panonia son una misma persona, circunstancia que permite al sujeto cuestionarse su identidad a partir de la confrontación con el otro al que necesita para ser él mismo, como ya apuntamos con anterioridad.

32 En el relato unamuniano también están presentes otros hermanos bíblicos: Esaú y Jacob: "La Escritura dice que en el seno de Rebeca se peleaban ya Esaú y Jacob. ¡Quién sabe si un día no concebirás tú dos mellizos (....) y se pelearán y se odiarán ya desde tu seno y antes de salir al aire y a la conciencia! Porque ésta es la tragedia humana, y todo hombre es como Job, hijo de contradicción" Unamuno, Miguel de: Abel Sánchez, Cátedra, Madrid, 1998, pág. 177.

33 Unamuno, Miguel de: Teatro completo, Aguilar, Madrid, 1973, pág. 987.

34 Ibídem, pág. 981.

35 Ibídem, pág. 982. 
Además de en este cuento, dos ejemplos de identidades que necesitan alteridades para conformarse como individuos y que simultáneamente abordan el tema del doble los encontramos en "El duelo" y "El otro duelo". En el primer texto, las protagonistas, Clara Glencairn de Figueroa y Marta Pizarro, ${ }^{36}$ poseen en común su dedicación a la pintura, que paralelamente a las disquisiciones heréticas del cuento anterior, será el elemento alrededor del cual orbiten sus (des)encuentros:

La vida exige una pasión. Ambas mujeres la encontraron en la pintura o, mejor dicho, en la relación que aquélla les impuso. Clara Glencairn pintaba contra Marta y de algún modo para Marta; cada una era juez de su rival y el solitario público. En esas telas, que ya nadie miraba, creo advertir, como era inevitable, un influjo recíproco. ${ }^{37}$

$\mathrm{Y}$ al igual que en el relato mencionado, tras la muerte de Clara, "Marta comprendió que su vida ya carecía de razón" ${ }^{38}$ De nuevo, la unici$\mathrm{dad} /$ identidad necesita de la duplicidad/otredad para configurarse.

Esta circunstancia, aunque con matices distintos, la encontramos de nuevo explicitada en "La casa de Asterión". Si bien el minotauro borgesiano reclama su individualidad al afirmar: "El hecho es que soy único", ${ }^{39} \mathrm{en}$ el fondo lo que está poniendo de manifiesto es la evidencia de su profunda soledad. Frente a la realidad laberíntica que lo envuelve juega con el objetivo de paliarla mientras espera la llegada de Teseo como rendención. El juego le permite dar el paso del yo al nosotros, se duplica por la acción lúdica y el doble funciona en este caso como compensación imaginaria de la alteridad: ${ }^{40}$

...de tantos juegos el que prefiero es el de otro Asterión. Finjo que viene a visitarme y que yo le muestro la casa. Con grandes reverencias le digo: Ahora volvemos a la encrucijada anterior o Ahora desembocaremos en otro patio o Bien decía yo que te gustaría la canaleta o Ahora verás una cisterna que se llenó de arena o Ya verás como el sótano se bifurca. A veces me equivoco y nos reímos buenamente los dos. ${ }^{41}$

36 Una historia similar, que acentúa la relación de odio existente entre los protagonistas, la encontramos en "El otro duelo" donde Carmen Silveira y Manuel Cardoso reducen sus vidas al odio que se profesan, convirtiéndose paulatinamente y sin sospecharlo en esclavos uno del otro.

37 Borges, Jorge Luis: Obras Completas, vol. II, Emecé, Barcelona, 1999, pág. 432.

38 Ibídem, pág. 432.

39 Borges, Jorge Luis. Obras Completas, vol. I, Emecé, Barcelona, 1999, pág. 569.

$40 \mathrm{Si}$ el desdoblamiento posee como referente un animal, éste suele ser utilizado bien como símbolo de la alienación, la soledad, la incomunicación y la precariedad de las relaciones del hombre con el medio y con la sociedad, o como metáfora para revelar fobias, reflejar la pérdida de identidad o expresar dilemas de la conciencia.

41 Borges, Jorge Luis. Obras Completas, vol. I, Emecé, Barcelona, 1999, pág. 570. 
Por otro lado, el "monólogo" pone de manifiesto el carácter dialógico de todos nuestros pensamientos. El diálogo no surge tanto como una invitación sino como una necesidad de la identidad en un mundo de otros. La actividad dialógica es el compromiso sustancial que da lugar al yo y que lo define desde sus orígenes como algo híbrido, como un cruce, como un injerto ${ }^{42}$ como si realmente fuéramos hombres/toro habitantes de los múltiples laberintos de la mismidad. Así, la alteridad se encuentra en el interior del yo, en el diálogo, en la relación otro/yo. Esta necesidad del otro implica un énfasis de lo intersubjetivo en detrimento del solipsismo que pretende descentralizar. Por este motivo, en los cuentos en los que nos vamos a detener a continuación el descubrimiento de la Otredad esta vinculado a la iluminación de nuestra propia identidad, a una anagnórisis que acaba desvelando nuestro propio destino. El encuentro con el otro, que actúa como espejo, tiene por tanto valor de autognosis ${ }^{43}$ ya que la imagen del doble nos permite y posibilita un enriquecimiento vital al mostrarnos zonas ignoradas o remotas de nuestra identidad. ${ }^{44}$ Por ejemplo, en "Biografía de Tadeo Isidoro Cruz (1829-1874)", la toma de conciencia que se realiza en el encuentro con el otro simboliza la asunción del destino y la revelación de la falsedad de los antagonismos. Alteridad e identidad son conceptos relacionales que se afirman recíprocamente en su diferencia y singularidad: "Comprendió que un destino no es mejor que otro, pero que todo hombre debe acatar el que lleva adentro. (...) Comprendió su íntimo destino de lobo, no de perro gregario; comprendió que el otro era él". ${ }^{45}$

Desde este punto de vista, lo importante sería desarrollar prácticas discursivas que incluyeran una doble trayectoria, un ir y venir asentado en el espacio de lo trans- como punto de partida, como punto de referencia, a partir del cual poder "llegar a ser". Este espacio de trans-ición no habría de conceptualizarse como un ámbito donde se den relaciones de oposición sino como la esfera del encuentro, ${ }^{46}$ puesto que en toda actividad, tanto

42 Ponzio, Augusto: La revolución bajtiniana. El pensamiento de Bajtín y la ideología contemporánea, Cátedra, Madrid, 1998, págs. 26-27.

43 Huici, Adrián: "Borges y nosotros. De la metafísica a la literatura" en: Bargalló, Juan: Identidad y alteridad: aproximación al tema del doble, Alfar, Sevilla, 1994, pág. 255.

44 Morello-Frosch, Marta: "El personaje y su doble en las ficciones de Cortázar" en VV.AA.: Homenaje a Julio Cortázar; variaciones interpretativas en torno a su obra, Las Américas, Nueva Cork, 1972, págs. 331-332.

45 Borges, Jorge Luis: Obras Completas, vol. I, Emecé, Barcelona, 1999, pág. 563.

46 Romero López, Dolores (ed.): Naciones Literarias, Anthropos, Barcelona/Madrid, 2006, págs. 171-172. 
explícita como implícitamente, se encuentra presente el otro, los otros, en definitiva, el yo, nosotros. ${ }^{47}$

En esta línea, "Historia del guerrero y la cautiva" representaría la ruptura con la pesadilla eurocéntrica y racionalista a través de la figura de la inglesa/araucana que personifica el encuentro con la otredad. Apelando al arquetípico Droctufl, Borges hace participar del destino universal, de una única historia, los avatares de la vida de su abuela y la cautiva. La remisión a las vidas antagónicas de las dos mujeres inglesas es el elemento que el narrador utiliza para realizar el tránsito y acceder al territorio de la barbarie. Este viraje resulta sustancial, ya que el narrador se sitúa en la misma localización "agora-heterofóbica" desencadenada por el abandono de "la india rubia" y su inmersión en lo otro. Según la interpretación de Adriana Berguero, la identidad de la cautiva es atroz por su carácter híbrido, al quebrar el pacto endogámico y "corporizar el horror heterofóbico al mestizaje", puesto que, en este caso, el cuento "no significará el sitio para la reversión o reivindicación histórica y cultural de los espacios periféricos", sino la demarcación del riesgo del espacio intersubjetivo. ${ }^{48}$ En este sentido, la violencia contra lo otro puede derivar de la realización de un acto reflejo como expone Borges en "Historia de Jinetes": "Los mongoles tomaron Pekín, pasaron a degüello por la población. (...) Queman y matan, no por sadismo, sino porque se encuentran desconcertados". ${ }^{49}$ A la postura anteriormente expuesta, que define la frontera borgesiana "como espacio metafórico transhistorizante y desterritorializador de la condición ontología del sujeto", ${ }^{50}$ contraponemos la postura de Sarlo, afín a lo que venimos exponiendo, para quien tanto el guerrero como la cautiva abandonan el lado al que pertenecen al estar impulsados por la fascinación del otro. ${ }^{51}$ En este sentido, relacionaremos el término "frontera" con el de utopía puesto que simboliza la esperanza de acceso a la tierra prometida. La dialéctica centro/periferia, ejemplificada en la frontera, supone al mismo tiempo la construcción paradójica de un obstáculo y un puente hacia lo otro. Esta circunstancia implica encuentro y huida, enriquecimiento y pérdida. ${ }^{52}$ Hay que

47 Peñalver, Patricio: Del espíritu al tiempo: lecturas de "El ser y el tiempo" de Heidegger, Anthropos, Barcelona, 1989, pág. 144.

48 Berguero, Adriana J: Haciendo camino. Pactos de la escritura en la obra de Jorge Luis Borges, UNAM, México, 1999, pág. 493.

49 Borges, Jorge Luis. Obras Completas, vol. I, Emecé, Barcelona, 1999, pág. 153.

50 Berguero, Adriana J: Haciendo camino. Pactos..., pág. 499.

51 Sarlo, Beatriz: Borges, un escritor..., pág. 99.

52 Ricci, Gabriela: Las redes invisibles..., pág. 88. 
descubrir al otro e incorporar un concepto de identidad que aúne lo diferente y lo semejante, que abarque aspectos particulares y universales, derribando las fronteras epistemológicas de una identidad esencialista que tome lo contingente por necesario y lo temporal por eterno. ${ }^{53}$

Por su parte, en "Guayaquil" la figura del otro, concretizada en Zimmerman, historiador alemán de origen judío, desestabiliza el discurso totalizador de lo nacional, de la identidad absoluta tanto individual como colectiva. La alteridad ataca las fantasmagorías nacionalistas al proponer un concepto de identidad cultural que incluye combinaciones y múltiples posibilidades que lucharían contra un concepto de identidad rígido y prefijado. ${ }^{54}$ Siguiendo a Augué, es precisamente la exclusión del Otro, que pretende el historiador argentino del relato, aquello que más amenaza a la identidad que intenta defender apelando a la rancia genealogía patria. En Borges, la legitimación de la verdad no precisa de concepciones históricas y científicas o grandes metarrelatos que estructuren la cultura, es más, la intención última sería desvelar los intereses y trampas que existen detrás de cualquier sistema organizador - filosofía, ciencia, historia - declarados transitorios por y en el espacio de la literatura ${ }^{55}$ En este sentido, la pérdida de la racionalidad finalista da lugar a la posibilidad del surgimiento de un lugar alternativo al lugar común en donde existe una correspondencia entre palabra y cosa. Desde este punto de vista, podríamos establecer una conexión con el concepto de "heterotopía" de Foucault como elemento que pone de relieve los límites de la razón y del pensamiento discursivo. Las heterotopías manifiestan la sospecha de que existe un desorden que reivindica los fragmentos de una gran cantidad de órdenes posibles, permitiendo pensar, acercarnos y plantearnos la posibilidad de existencia del otro. ${ }^{56}$

Desde esta perspectiva, la intersubjetividad depende del deseo primordial del otro que ejerce un efecto complementario a nuestra identidad. ${ }^{57}$ En este sentido, el otro, entendido como "otra persona" o como "el extraño", "el alieno", es igualmente inseparable del yo quien lo necesita para cons-

53 Gómez García, Pedro: "Las desilusiones de la 'identidad'. La etnia como pseudoconcepto" en Gómez García, Pedro (coord.): Las ilusiones de la identidad, Cátedra, Madrid, 2000, págs. 30-31.

54 Panesi, Jorge: Críticas, Norma, Buenos Aires, 2004, págs. 144-145.

55 Louis, Annick (comp.): Enrique Pezzoni, lector de Borges, Sudamericana, Buenos Aires, 1999, págs. 90-97.

56 Massuh, Gabriela: Borges: una estética del silencio, Editorial de Belgrano, Buenos Aires, 1980, pág. 54.

57 Moreno, César: "El deseo de otro o la fascinación de proteo" en Bargalló, Juan: Identidad y alteridad: aproximación al tema del doble, Alfar, Sevilla, 1994, pág. 41. 
truir su mundo y construirse, a la vez que se muestra refractario a toda categoría que quiera eliminar su alteridad. ${ }^{58}$ Así, el autoconocimiento se produce únicamente cuando me manifiesto para el otro, sólo a través del otro, ya que el aislamiento y la cerrazón en sí mismo implica la pérdida de la propia identidad. ${ }^{59}$ Lo que interesaría, por tanto, no es aquello que acaece en la interioridad, sino lo ocurre en la zona de frontera, en el umbral donde se da la interacción de lo propio y lo ajeno, en ese "todo cada uno" que se vuelca hacia y "en otro uno" para formar constelaciones. ${ }^{60}$

Recibido el 16 de febrero de 2007 Aceptado el 10 de enero de 2008

58 Ponzio, Augusto: La revolución bajtiniana..., pág. 197.

59 Bajtín, Mijaíl: Estética de la..., pág. 327.

60 Paz, Octavio: Ladera Este, Premiá, México, 1969, pág.134. 